\title{
RESEARCH ON PREDICTION ABOUT FRUIT TREE DISEASES AND INSECT PESTS BASED ON NEURAL NETWORK
}

\author{
Gang Liu', Hongyan Shen ${ }^{1}$, Xuehong Yang ${ }^{1}$, Yinbing $\mathrm{Ge}^{2}$ \\ 1 China Agricultural University, Beijing, P.R. China pac@cau.edu.cn
}

2 Currently study in Utah State University, Logan, UT, USA

Abstract: $\quad$ Fruit tree diseases and insect pests always occur which are related to weather. According to weather information and occurrence status of fruit tree diseases and insect pests in orchards of the Qixia county for 11 years, the MATLAB neural network toolbox was used to build up the prediction system about fruit tree diseases and insect pests based on Back Propagation (BP) neural network. Then the system was trained by the history record data. Finally, the ring spot, a fruit tree disease, was chosen as the research object to compare the predicted value with the actual value. The results indicate that the system can predict accurately, run fast, and function robustly. The system can be applied for prediction about fruit tree diseases and insect pests.

Key words: neural network, MATLAB, diseases and insect pests prediction

\section{INTRODUCTION}

Since the 90s of the 20th century, fruit tree diseases and insect pests in our country has occurred frequently, disaster area has increased by $30 \%$ compared with the status of the $80 \mathrm{~s}$, and the average yield loss per year has been more than $25 \%$. In recent years, pesticide is used mainly to control fruit tree diseases and insect pests and is used superfluously and abusively. It has influenced the fruit quality badly and endangered the human health. Every 
country in the world has started to pay more and more attention to it. During

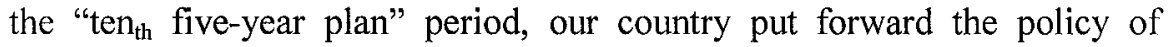
"prevention is primary combining with management" to control the agriculture disaster. A lot of plant disaster monitor and forecast stations have been established in many areas. However, the prediction function of these stations did not work well because the prediction technique was behindhand and the prediction accuracy was low. Therefore, the monitor, prediction, control and decision-making technology based on artificial intelligence have become the principal research direction in the prediction about fruit tree diseases and insect pests in our country.

Yantai city is one of the important areas to plant fruit tree in the north of our country. There are a variety of fruit tree diseases and insect pests in a wide range of areas. Recently, intelligentized information technology has been applied in research and practice of plant protection. Because the weather conditions are important factors to the occurrence and development of fruit tree diseases and insect pests, most expert systems depend on probability analysis from the history data and lead to imprecise diagnosis and prediction.

Artificial neural network (ANN) can simulate, to some extent, how neural network in human brain deals with, searches and stores information. ANN can obtain knowledge expediently and quickly, organize and study by itself, be adapted to environment changes and deal with nonlinear problems. Based on Back Propagation (BP) neural network, MATLAB neural network toolboxes were used in this paper to establish a prediction system about fruit tree diseases and insect pests. The system can predict the occurrence of fruit tree diseases and insect pests according to the weather data from 1992 to 2002 and the occurrence situation of diseases and insect pests in Qixia county of Yantai city.

\section{MATERIALS AND METHODS}

\subsection{Data Acquisition}

There are many kinds of fruit tree diseases and insect pests such as foulbrood, fruit rotted disease, defoliated disease, ring spot, mite, lyonetid moth, aphide, fruit moth in Qixia county of Yantai city. Weather, biological, spatial data, etc. are mainly used in the diagnosis and prediction about fruit tree diseases and insect pests. The weather data including average temperature, rainfall, rainfall days, air humidity, wind speed and wind direction are obtained from April to August from 1992 to 2002 in Qixia 
county weather station. Correspondingly, fruit tree diseases and insect pests occurrence situation were obtained from May to September every year by searching data and consulting experts in plant protection. This research is completed with the cooperation of the agriculture information center in Yantai city.

\subsection{The Construction of Artificial Neural Network}

Three-layer ANN is the most widely applied in the field of diagnose and prediction. Figure 1 shows the ANN model. The standard three-layer network topological structure is made up of input layer, hidden layer and output layer. The nonlinear mapping from input to output is realized by using connective weight matrixes from input layer to hidden layer and from hidden layer to output layer. ANN always adopts BP algorithm. After the neural network is trained with samples, the connective weight values such as $\mathrm{W}_{\mathrm{ij}}$ and $\mathrm{W}_{\mathrm{jk}}$ among neural nodes are adjusted constantly according to errors between expectation and actual output. Eventually, the output of network, determined by $\mathrm{W}_{\mathrm{ij}}$ and $\mathrm{W}_{\mathrm{jk}}$, come close to the expectation in desired precision. Hence, the self-study of ANN can be well solved.

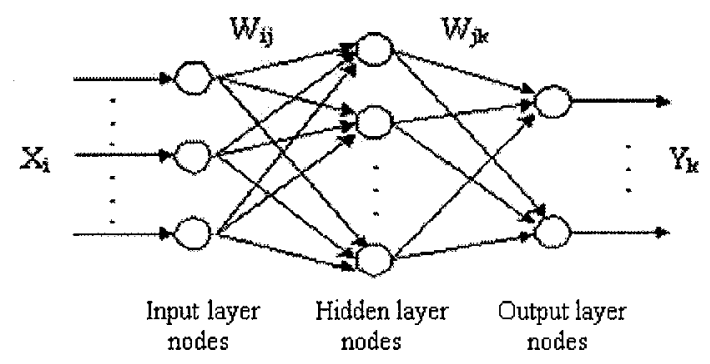

Figure 1 Artificial neural network model

\subsubsection{The Study Algorithm of BP Artificial Neural Network}

BP ANN study algorithm adopts gradient descent. The basic idea of this algorithm is to change the network weight values according to the minimum value of the sum-square error between expectation and actual output.

Error function $\mathrm{J}(\mathrm{W})$ is defined as follows : 


$$
J(W)=\frac{1}{2}(Y(k)-\bar{Y}(W, k))^{2}
$$

where, $Y(k)$ is the expectation, $\bar{Y}(W, k)$ is the actual output of the neural network, and $\mathrm{W}$ is the vector consisting of all weight values in the network. Gradient descent is to revise the value of $W(k)$ along the negative gradient descent of $J(W)$ till $J(W)$ reaches the minimum. It is expressed mathematically as:

$$
W(k+1)=W(k)+\left.p(k)\left(-\frac{\partial J(W)}{\partial W}\right)\right|_{W=W(k)}
$$

where, $p(k)$ is the variable controlling the revised speed of weight values.

In the nth iterative output of BP ANN, $y_{j(n)}$ is the jth neural cell output, and $\mathrm{d}_{\mathrm{j}(n)}$ is the corresponding output (it can be provided by training sample). The error in this neural cell is:

$$
e_{j}(n)=d_{j}(n)-y_{j}(n)
$$
is:

Square error in the neural cell $\mathrm{j}$ is $\frac{1}{2} e_{j}^{2}(n)$. The sum-square error in output

$$
E(n)=\frac{1}{2} \sum_{j \in c} e_{j}^{2}(n)
$$

where, $\mathrm{c}$ contains all of output neural cells, and $\mathrm{n}$ is the total number of training samples. The average of square error is:

$$
E_{A V}=\frac{1}{N} \sum_{n=1}^{N} E(n)
$$

where, $\mathrm{E}_{\mathrm{AV}}$ is the study object function. The purpose of the study is to make $\mathrm{E}_{\mathrm{AV}}$ minimum.

\subsubsection{The Node Number in Hidden Layer}

The node number in hidden layer is related to the complexity of problems and can directly influence the network nonlinear capability. It can be 
increased to improve the network training precision. This system uses experiential formula as follows to determine the node number in hidden layer:

$$
p=\left\{\begin{array}{lc}
n+0.618(n-m) & n>=m \\
m-0.618(m-n) & n<m
\end{array}\right.
$$

where, $\mathrm{n}$ is the input node number, $\mathrm{m}$ is the output node number, and $\mathrm{p}$ is the hidden node number.

\subsubsection{The Study Parameters in Artificial Neural Network}

1. The Initialized Weight Values

Before study, the network must be initialized. Initialization is mainly to set random numbers less than 1 to all connective weight values between neural nodes in BP ANN model. Since the system is nonlinear, initialized weights have an effect on whether the study reaches partial minimum and converges and how long the training takes. Generally, it is expected that the output of every neural node comes close to 0 after the weights are added. In this way, it can ensure that the weight value of every neural node can be adjusted when their Sigmoid active functions change. Therefore, the initialized values are commonly random number within $[-1,1]$. The research and experiment have shown, if the initialized values are mostly selected around 0 , the network might not converge. In this system, the initialized weight values within $[-5,5]$ are set so as to accelerate convergence.

2. The Learning Rate

The learning rate determines the variety of weight values produced in each cycle. Higher learning rate may lead to instability of the system. Lower learning rate may make the training longer and convergence rate slower. The learning rate is associated with the network size that indicates the node number of input and output in the network. Based on experiential formula, $\eta_{0}$ is chosen as the initialized value of learning rate $\eta$.

$$
\eta_{0}=\frac{1}{\sqrt{p}}
$$

where, $\mathrm{p}$ is the node number in hidden layer.

During the study, the iterative times obviously decreases when $\eta$ increases. Therefore, dynamic adjustment is utilized to control learning rate 
in this system. When learning rate lowers, $\eta$ is increased slowly. When the network is emanative, $\eta$ is decreased quickly. The algorithm is as follows:

When $\mathrm{E}(\mathrm{t})-\mathrm{E}(\mathrm{t}-1)>0.05 \mathrm{E}(\mathrm{t}-1)$, the network converges quickly and each value keeps invariable;

When $E(t)-E(t-1)<0$, the network is emanative, and $\eta=\eta / 2$;

When $0<\mathrm{E}(\mathrm{t})-\mathrm{E}(\mathrm{t}-1)<0.05 \mathrm{E}(\mathrm{t}-1)$, the convergence rate of the network is slow, and $\eta=1.3 * \eta$.

\subsubsection{The Pretreatment of Sample Data}

Since data are not always in the same dimension, they should be mapped within $[-1,1]$ and normalized. This can improve the training speed of neural network. The algorithm is as follows:

$$
x^{\prime}=\frac{x_{\max }-x}{x_{\max }-x_{\min }}
$$

where $x^{\prime}$ are the data after normalization, $x$ are the raw data, $x_{\max }$ is the maximum value of the raw data and $x_{\min }$ is the minimum value of the raw data.

Because many weather factors influence the occurrence of fruit tree diseases and insect pests, several weather factors well related to fruit tree diseases and insect pests are selected for neural network prediction model through research and data analysis. These weather factors are average temperature, rainfall, rainfall days and air humidity from April to August during 1992-2002 in Qixia county. Correspondingly, the main kinds of fruit tree diseases and insect pests are foulbrood, fruit rotted disease, defoliated disease, ring spot, mite, lyonetid moth, aphide, fruit moth from May to September. Table 1 shows the data after normalization for fruit tree disease of ring spot in Qixia county in 1992. According to the normal grade issued by national station of plant protection, fruit tree diseases and insect pests grades contain: bad, less bad, intermediate, light, lighter and the normalization data are: $0.9,0.7,0.5,0.3,0.1$.

Table 1. Sample data after normalization

\begin{tabular}{llllll}
\hline Month & $\begin{array}{l}\text { Average } \\
\text { Temperature }\end{array}$ & Rainfall & $\begin{array}{l}\text { Rainfall } \\
\text { Days }\end{array}$ & $\begin{array}{l}\text { Average } \\
\text { Humidity }\end{array}$ & Grades) \\
\hline 4 & 0.832 & 0.765 & 0.942 & 0.941 & 0.1 \\
5 & 0.517 & 0.592 & 0.623 & 0.768 & 0.5 \\
6 & 0.396 & 0.401 & 0.590 & 0.352 & 0.9 \\
7 & 0.204 & 0.232 & 0.383 & 0.310 & 0.3 \\
8 & 0.096 & 0.130 & 0.095 & 0.024 & 0.1 \\
\hline
\end{tabular}




\section{RESULTS AND ANALYSIS}

In terms of different growth seasons of fruit tree, several occurrence periods of fruit tree diseases and insect pests are distinguished. These prediction models for fruit tree diseases and insect pests in these growth seasons are made respectively. Forty neural network prediction models may be established according to weather factors from April to August, 5 prediction periods from May to September for fruit tree diseases and insect pests and 8 kinds of diseases and insect pests. However, some kinds of diseases and insect pests always occur in some centralized months, for example, the ring spot disease in Qixia county mainly occurs in June. Hence, only 14 neural network models are built up in this system.

Neural network prediction system uses MATLAB neural network toolbox to establish training program database, neural network weight and threshold value databases. These weight and threshold values have been trained successfully. For each neural cell subsystem, the node number in input layer is 4 and the input $x_{i}(i=1 \ldots 4)$ represents average temperature, rainfall, rainfall days, and air humidity respectively. The node number in output layer is 1 and $y$ is used to present the occurrence grades of fruit tree diseases and insect pests, such as bad, less bad, middling, light, lighter. BP network algorithm provided by MATLAB is as follows:

$p=$ [average temperature, rainfall, rainfall days, air humidity];

$\mathrm{t}=$ [occurrence grades of diseases and insect pests];

Initialized function is newff:

net $=$ newff(minmax $(p),[a, 1],\{$ 'Transig', 'Purelin' $\}$, 'Trainlm');

This is to establish a three-layer BP network data structure called 'net'. The node number in hidden layer is ' $a$ ', and the recursion function is 'Transig'. The node number in output layer is 1 , and the recursion function is 'Purelin'. The training algorithm function is 'Trainlm'. In this system, ' $a$ ' is selected as 6 according to eq. (6).

Before training, the parameters as follows must be evaluated and the others are set as default:

Maximum of training times: net.trainParam.epochs $=20000$;

Minimum of grads difference: net.trainParam.min-grad $=0.01$;

Goal value of accuracy: net.trainParam.goal $=0.01$;

Display interval: net.trainParam. show $=100$;

Initialized learning speed: net.trainParam.1r $=0.4$;

Network training function is:

[net, $\mathrm{tr}]=$ train $($ net, $\mathrm{p}, \mathrm{t})$;

This function is to train the network and save the network structure into the array 'net'. 
With the input of the weather data in May and the ring spot disease in June in Qixia county, the network is firstly initialized and then trained by function "Trainlm" for 18546 times. Eventually, the sum-square error of the network reaches the requirement of goal error. Figure 2 shows the change of, sum-square error during training. The curve indicates that sum-square error decreases with the increase of training times. When the error reaches the expectation, the training stops.

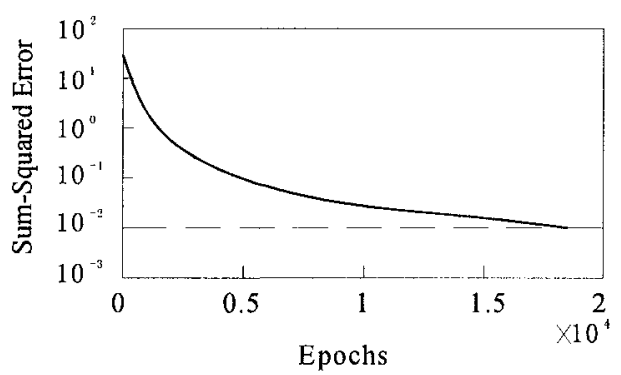

Figure 2 The change of sum-square error with training times

The data of weather and fruit tree diseases and insect pests from 1992 to 2000 are selected as the raw data of network training and the data from 2001 to 2002 are selected as validation data. Table 2 shows the comparison between the prediction value and the actual value about the ring spot disease in Qixia county in June 2001 and 2002.

Table 2 Comparison of Prediction Value with Actual Value

\begin{tabular}{llllll}
\hline $\begin{array}{l}\text { Month \& } \\
\text { Year }\end{array}$ & $\begin{array}{l}\text { Prediction } \\
\text { Value }\end{array}$ & $\begin{array}{l}\text { Prediction } \\
\text { Grades }\end{array}$ & Actual Value & Actual Value & Error Rate \\
\hline 2001.6 & 0.96427 & Bad & 0.9 & Bad & $7.14 \%$ \\
2002.6 & 0.76503 & Less Bad & 0.7 & Less Bad & $9.29 \%$ \\
\hline
\end{tabular}

Table 2 shows that the model error between the prediction value and the actual value is small. This indicates that the method is feasible in which MATLAB neural network toolbox is used to predict fruit tree diseases and insect pests based on BP network.

\section{CONCLUSION}

Based on the basic theory of artificial neural network, MATLAB neural network toolbox has been used to realize BP network algorithm in different 
conditions and to establish 14 neural network models. The prediction results are satisfactory from the comparison between the prediction value and the actual value of the ring spot disease in June 2001 and 2002. In this study, eight fruit tree diseases and insect pests are chosen as the research object and 4 weather factors are selected in every month as prediction condition. However, it is noteworthy to point out that the number of fruit tree diseases and insect pests increases with changes of climate and management of fruit tree in recent years. Different fruit tree diseases and insect pests are influenced by different weather factors. So the model in the research should be further improved correspondingly.

The prediction system about fruit tree diseases and insect pests takes the advantage of $\mathrm{BP}$ in prediction to avoid establishing complex mathematic models. After it is extended and improved, the system may be suitable for diagnosis and prediction of many kinds of crop diseases and insect pests and is valuable to be a reference.

\section{ACKNOWLEDGEMENT}

This program is supported by Chinese National Funded High Science and Technology Research Project (863 project) - the long-distance diagnosis platform of plant diseases and insect pests based on network 2002AA243031.

\section{REFERENCES}

[1] Mie Mie Thet Thwin, Tong-Seng Quah: Application of Neural Networks for Software Quality Prediction Using Object-Oriented Metrics. The Journal of Systems and Software. Vol. 76 (2005) 147-156

[2] D.Ashish, G.Hoogenboon, R.W.McClendon: Land-Use Classification of Gray-Scale Aerial Images Using Probabilistic Neural Networks. Transactions of the ASAS. Vol. 47(5)(2004) 1813-1820

[3] C.Yu, W.J.Northcott, G.F.McIsaac: Development of an Artificial Neural Network for Hydrologic and Water Quality Modeling of Agricultural Watersheds. Transactions of the ASAS. Vol. 47(1)(2004) 285-290

[4] L.O.Odhiambo, R.S.Freeland, R.E.Yoder, J.W.Hines: Investigation of a Fuzzy-Neural Network Application in Classification of Soils Using Ground-Penetrating Rader Imagery. Applied Engineering in Agriculture. Vol.20(1)(2004)109-118

[5] M.P.Bange, S.A.Deutscher, D.Larsen, D.Linsley, S.Whiteside: A Handheld Decision Support System to Facilitate Improved Insect Pest Management in Australian Cotton Systems. Computers and Electronics in Agriculture. Vol.43(2)(2004)131-148 
[6] Lo.Tedeschi, D.G.Fox, P.J.Guiroy: A Decision Support System to Improve Individual Cattle Management. 1. A Mechanistic, Dynamic Model for Animal Growth. Agricultural System. Vol.79(2)(2004)171-204

[7] Mingyao Zhou, Hongwei Chen: Artificial Neural Network Model for Soil Moisture Forecast in Deficit Irrigation Rice Field. CIGR International Conference. Beijing, China (2004)

[8] Zailin Huo, Haibin Shi, Dongmei Qiao: Study on Artificial Neural Network Model for Crop Response to Soil Water-Salt. CIGR International Conference. Beijing, China (2004)

[9] Zhang X, Engel B. A., Benady N.: Locating Melons Using Artificial Neural Networks. ASAE Paper (1992)

[10] Muslim Abbas Zaidi, Haruhiko Murase: Evaluation of Seeding Vigour Using Neural Network Model under Clinostated Conditions. International Conference on Agricultural and Science and Technology. Beijing, China (2001) 504 507

[11] Xiumei Li, Xiaojun Qiao, Tao Ye: A New Fuzzy Neural Network Controller Applied in The Greenhouse. Progress of Information Technology in Agriculture. Beijing, China (2003) 546-549

[12] Hongchun Yuan, Fanlun Xiong: A Novel Approach For Extracting Rules from Trained Neural Network. International Symposium on Intelligent Agricultural Information Technology. Beijing, China (2000) 305 309

[13] S.T.Drummond, K.A. Sudduth, A.Joshi, N.R.Kitchen: Statistical and Neural Methods for Site-Specific Yield Prediction. Trans ASAE.(2003) 46(1):5-14

[14] Y.He, Q Zhang, L.Feng. Engine Real-time Fault Diagnosis Using Neural Networks. ASAE Paper No. 701P0502. Chicago, Illinois, (2002) USA:ASAE

[15] M.A Kramers, C.G.M. Conjin, C. Bastiaansen. An expert system for diagnosing flowerbulb diseases, pests and non-parasitic disorders. Agricultural systems, Vol58, No.1,PP 57-85, (1998) 